\title{
Optimal Effectiveness of BDNF for Fetal Nigral Transplants Coincides with the Ontogenic Appearance of BDNF in the Striatum
}

\author{
David M. Yurek, ${ }^{1}$ Susan B. Hipkens, ${ }^{1}$ Stanley J. Wiegand, ${ }^{2}$ and C. Anthony Altar ${ }^{2}$ \\ ${ }^{1}$ Department of Surgery/Neurosurgery and Anatomy and Neurobiology, University of Kentucky College of Medicine, \\ Lexington, Kentucky 40536, and 2Regeneron Pharmaceuticals, Inc., Tarrytown, New York 10591
}

Transplantation of fetal nigral dopamine neurons into the caudate and putamen of Parkinson's disease patients produces limited symptomatic relief. One approach to augment the outgrowth and function of nigral grafts includes exposure of the graphs to neurotrophic factors; however, the temporal requirements for optimizing these actions are unknown. The present study characterized the ontogeny of brain-derived neurotrophic factor (BDNF) in the rat striatum and used this information to define and evaluate three distinct periods of BDNF infusion into fetal nigral grafts transplanted into the striatum of rats with experimental Parkinson's disease. At postnatal day 1 (P1), BDNF and dopamine were measured at 17 and $27 \%$ of peak levels, respectively, that occurred at P27 for both. Both compounds showed their greatest surge between P7 and P20, increasing from $40 \%$ to $\sim 95 \%$ of peak levels. Exogenous BDNF infused into transplants during weeks 1 and 2 after the transplantation, which coincide with the developmental period

Transplantation of fetal nigral dopamine neurons into the neostriatum of Parkinson's disease patients is a relatively new procedure that produces a limited amount of symptomatic relief (Olanow et al., 1996). Because this limited relief is related to the modest survival and outgrowth of the transplanted dopamine neurons, the identification of growth factors that improve these aspects of transplanted nigral dopamine neurons has direct clinical potential. In fact, over a dozen growth factors have since been identified that support the survival and/or differentiation of cultured fetal dopaminergic neurons. The localization of their mRNAs in the basal ganglia, including midbrain dopaminergic neurons, suggests that these factors may confer endogenous trophic support for dopaminergic neurons in vivo (Lindsay et al., 1993, 1994). These factors include the neurotrophins, brainderived neurotrophic factor (BDNF), neurotrophin-3 (NT-3), neurotrophin-4/5 (NT-4/5), platelet-derived growth factor (PDGF), epidermal growth factor and its homolog transforming grow th factor- $\alpha$, acidic and basic fibroblast growth factors (aFGFs and bFGFs), insulin and the insulin-like growth factors I and II, glial cell line-derived neurotrophic factor (GDNF), and ciliary neurotrophic factor (for review, see Altar et al., 1996).

Infusions of several of these factors can enhance the fiber

Received Feb. 11, 1998; revised May 13, 1998; accepted May 20, 1998.

This research was supported in part by Grants NS29994 and NS35890 (D.M.Y.), and by Regeneron Pharmaceuticals, Inc. We thank Amgen-Regeneron Partners for supplying BDNF for these studies.

Correspondence should be addressed to Dr. David M. Yurek, Department of Surgery/Neurosurgery, University of Kentucky College of Medicine, Health Sciences Research Building, Lexington, KY 40536-0305.

Copyright (C) 1998 Society for Neuroscience $\quad 0270-6474 / 98 / 186040-08 \$ 05.00 / 0$ embryonic day 14 (E14)-P7 for transplanted tissue, did not improve rotational behavior or enhance fiber outgrowth of transplanted dopamine neurons. Delaying the BDNF infusion until transplanted tissue was approximately P8-P21 greatly enhanced the effect on rotational behavior and doubled the area of dopamine fiber outgrowth from the transplants. Delaying the infusion until transplanted tissue was approximately P36-P49 failed to augment fiber outgrowth and decreased the behavioral function of transplants. Thus, the optimal effect of exogenous BDNF on the development of dopamine neurons in fetal nigral transplants occurs at a postnatal age when endogenous dopamine and BDNF show the greatest increases during the normal development of the striatum.

Key words: brain-derived neurotrophic factor; development; dopamine; Parkinson's disease; neural transplantation; neurotrophic factor; fiber outgrowth

outgrowth and behavioral effects of grafted fetal dopaminergic neurons in animal models of Parkinson's disease. These factors include bFGF and aFGF (Steinbusch et al., 1990; Giacobini et al., 1991; Mayer et al., 1993b; Takayama et al., 1995; Zeng et al., 1996), PDGF (Giacobini et al., 1993), and GDNF (Strömberg et al., 1993; Rosenblad et al., 1996; Wang et al., 1996). That the neurotrophins may play similar roles is supported by the localization in ventral midbrain dopamine neurons of the mRNAs for BDNF and NT-3 (Gall et al., 1992; Seroogy and Gall, 1993) and for the functional, high-affinity receptors for BDNF and NT-3, trkB and trkC, respectively (Squinto et al., 1991; Ebendal, 1992; Meakin and Shooter, 1992; Miranda et al., 1993). However, in an initial study, infusions of BDNF into fetal dopamine neuron transplants provided only a modest improvement in transplant development and no behavioral improvement beyond that obtained with the transplant alone (Sauer et al., 1993). In subsequent studies, continuous infusions of BDNF into the transplant site improved transplant growth, integration, and behavioral function (Yurek et al., 1996). Similar infusions of NT-4/5 stimulated dopamine fiber outgrowth (Haque et al., 1996). Methodological differences between the Sauer et al. (1993) and Yurek et al. (1996) studies that include the mode of BDNF administration (intermittent vs continuous), the transplant type (cell suspension vs tissue chunk), and the dose of BDNF (12 vs $36 \mu \mathrm{g} / \mathrm{d}$ ) may have contributed to the different outcomes.

Although the later studies indicate that BDNF may be a useful adjuvant to promote the survival and function of transplanted dopamine neurons, the temporal requirements of treating such grafts with exogenous growth factors including BDNF are un- 
known. One guideline for determining the temporal requirement may be to identify the developmental age when BDNF is maximally expressed in the striatum and how this coincides with the normal ontogeny of dopamine innervation. The present study characterized the ontogeny of BDNF protein in the rat striatum and determined whether the appearance of BDNF coincided with the appearance of dopamine. This information was used to define and evaluate three distinct periods of BDNF infusion into fetal ventral mesencephalon grafts transplanted into the striatum of rats with experimental Parkinson's disease. These results were then compared with the effect exogenous BDNF had on the development and behavioral function of fetal ventral mesencephalic transplants after its infusion during the different periods of transplant development. An immediate BDNF infusion, during weeks 1 and 2 after the transplantation, was used because it coincides with the time Sauer et al. (1993) infused BDNF and because it corresponds to the late embryonic and early postnatal period when striatal BDNF was found to be very low. Infusions during weeks 3 and 4 after the transplantation replicated our previously effective infusion period (Yurek et al., 1996) and were used because this period corresponds to postnatal days 8-22 when BDNF was found to increase dramatically. A delayed BDNF inf usion during weeks 7 and 8 after the transplantation was added to define the longevity of the BDNF effect.

\section{MATERIALS AND METHODS}

6-Hydroxydopamine lesion. 6-Hydroxydopamine (6-OHDA) (Sigma, St. Louis, MO) was dissolved at a concentration of $2.0 \mu \mathrm{g} / \mu \mathrm{l}$ in $0.9 \%$ saline containing $0.2 \%$ ascorbic acid. Male Sprague Dawley rats (225-250 gm; Harlan Farms, Prattsville, Alabama) were anesthetized and placed in a stereotactic instrument. Each rat received a complete lesion of the right A9 and A10 dopamine nuclei and a near complete denervation of dopaminergic fibers innervating the right ipsilateral striatum by two injections of 6-OHDA at a rate of $1.0 \mu \mathrm{l} / \mathrm{min}$ for $3 \mathrm{~min}$. One injection was in the medial forebrain bundle (anteroposterior, -4.3 ; mediolateral, 1.2; and dorsoventral, -7.5$)$; the other was in the rostral pars compacta of the substantia nigra (anteroposterior, -4.8 ; mediolateral, 1.5; and dorsoventral, -7.5). All coordinates represent millimeter adjustments from bregma along the anteroposterior (AP) and mediolateral (ML) dimensions and below the dural surface (DV) with the top of the skull in a flat position.

At 3 weeks after the 6-OHDA infusion, the completeness of the unilateral nigrostriatal dopamine lesion was ascertained by the rotational response after systemic injections of the presynaptic dopamine-releasing drug D-amphetamine $(5 \mathrm{mg} / \mathrm{kg}$, i.p.) and the postsynaptic dopamine receptor agonist apomorphine $(0.2 \mathrm{mg} / \mathrm{kg}$, i.p.). Animals demonstrating $<5$ rotations/minute directed ipsilateral to the lesioned side after an amphetamine injection and $<100$ turns/hour directed contralateral to the lesioned side after apomorphine were excluded from the study. In addition, animals were excluded from the final analysis if a histological analysis revealed an incomplete lesion of tyrosine hydroxylase-positive neurons at the level of the pars compacta. All animal use procedures were approved by the University of Kentucky Animal Care and Use Committee and were in strict accordance with the National Institutes of Health Guide for the Care and use of Laboratory Animals.

Ventral mesencephalic tissue grafts. Four weeks after receiving 6-OHDA, recipient animals were anesthetized with sodium pentobarbital $(50 \mathrm{mg} / \mathrm{kg}$, i.p.) and placed in a stereotactic apparatus. At the same time, the ventral mesencephalon was dissected from embryonic day 13 (E13) to E15 fetuses obtained from time-pregnant Sprague Dawley rats (Harlan Farms) and stored individually in a cold, sterile, calcium- and magnesium-free buffer $\left(0.15 \mathrm{M} \mathrm{NaCl}, 8.0 \mathrm{~mm} \mathrm{Na}_{2} \mathrm{HPO}_{4}, 2.7 \mathrm{~mm} \mathrm{KCl}, 1.5\right.$ $\mathrm{mM} \mathrm{KHPO}_{4}, 26.0 \mathrm{~mm} \mathrm{NaHCO}, 0.1 \%$ glucose, $100 \mathrm{mg} / \mathrm{ml}$ streptomycin, and $2.5 \mathrm{mg} / \mathrm{ml}$ fungizone). The ventral mesencephalon from a single fetus was drawn into the blunt end of a 22 gauge spinal needle and stereotactically placed into the denervated striatum of the recipient animal at the following coordinates: anteroposterior, +0.5 ; mediolateral, +2.5 ; and dorsoventral, -5.5 (Yurek et al., 1996).

Intracerebral delivery of neurotrophic factors. Recombinant BDNF (Amgen-Regeneron Partners) was diluted in sterile PBS to a concentra-
Table 1. Infusion durations, after transplantation

\begin{tabular}{llll} 
& $1-2$ weeks & $3-4$ weeks & $7-8$ weeks \\
\hline Group I & BDNF & PBS & None \\
Group II & PBS & BDNF & None \\
Group III & None & None & PBS \\
Group IV & None & None & BDNF \\
Group V & None & None & None \\
\hline
\end{tabular}

tion of $3.0 \mu \mathrm{g} / \mu \mathrm{l}$. PBS vehicle or BDNF was infused into the transplant site using a model 2002 osmotic pump (flow rate $=0.5 \mu \mathrm{l} / \mathrm{hr}$; Alzet, Palo Alto, CA) during three different 2 week intervals after the transplant surgery: during weeks 1 and 2, which correspond to the period from E14 to postnatal day 7 (P7) for the transplant tissue, during weeks 3 and 4 , which correspond to P8-P21, and during weeks 7 and 8 , which correspond to P36-P49 (Table 1). For groups I and II, the first pump was implanted into a subcutaneous pocket within $10 \mathrm{~min}$ after the transplantation. The metal tubing input port of an osmotic pump connector (Plastic One, Roanoke, VA) was then attached to the free end of a $2 \mathrm{~cm}$ piece of polyethylene (PE) 60 tubing attached to the output port of the osmotic pump. The 5.2-mm-long metal cannula was lowered stereotactically to a point $0.3 \mathrm{~mm}$ dorsal to the transplant coordinates, and the cannula was permanently affixed to the skull with dental acrylic cement and anchor screws. Two weeks later, the animal was briefly anesthetized with a halothane-air mixture $(1.5 \%$ halothane at $2.0 \mathrm{l} / \mathrm{min})$. The location of the pump was identified by palpating the back region and then making an incision to expose the pump. The expired pump was removed from the subcutaneous pocket, the PE 60 tubing connection to the output port of the pump was severed, and the pump was discarded. A second fully loaded pump was connected to the severed end of the PE 60 tubing and inserted through the incision and into the subcutaneous pocket. The incision was closed with metal clips. Animals in groups III and IV received an osmotic pump and cannula implant from the beginning of the seventh to the end of the eighth week after the transplantation.

Rotational behavior testing. Rotational behavior was induced by a systemic injection of D-amphetamine $(5.0 \mathrm{mg} / \mathrm{kg}$, i.p.) or apomorphine $(0.2 \mathrm{mg} / \mathrm{kg}$, i.p.). Rats were placed inside opaque cylindrical chambers 16 inches in diameter that are positioned directly beneath a video camera. The video camera was connected to the Videomex $\mathrm{V}$ image motion computer system (Columbus Instrument, Columbus, $\mathrm{OH}$ ). The total number of $360^{\circ}$ clockwise or counterclockwise rotations was measured during each test interval. Before transplantation, lesioned rats were administered D-amphetamine or apomorphine, and those rats rotating $<5$ turns/minute to D-amphetamine and/or $<150$ turns/hour to apomorphine were excluded from the study. Rotational behavior after the transplantation was assessed using D-amphetamine only.

Quantitation of BDNF by ELISA. Within $10 \mathrm{~min}$ of death, the neostriata from both hemispheres were collected from Sprague Dawley albino rats at $1,4,7,10,14,20,27,35$, and $45 \mathrm{~d}$ after birth. Each tissue was immediately frozen and stored at $-70^{\circ} \mathrm{C}$. Subsequently, each tissue was thawed and homogenized for $30 \mathrm{sec}$ using a Polytron (Brinkman) on setting " 8 " in 25 volumes of $50 \mathrm{~mm}$ Tris- $\mathrm{HCl}, 0.6 \mathrm{M} \mathrm{NaCl}, 0.2 \%$ Triton $\mathrm{X}-100,1 \%$ BSA, $0.1 \mathrm{~mm}$ benzethonium chloride, $1.0 \mathrm{~mm}$ benzamidine, and $0.1 \mathrm{~mm}$ PMSF at $\mathrm{pH}$ 7.4. The homogenate was centrif uged for $30 \mathrm{~min}$ at $10,000 \times g$ at $4^{\circ} \mathrm{C}$. The supernatant was diluted $1: 4$ in water to establish isotonicity. The BDNF content of individual striata $(n=4-5$ per age group) was determined in $100 \mu \mathrm{l}$ aliquots of the supernatant with a double determinant ELISA, in which BDNF extracted from individual striata was captured with a BDNF-specific monoclonal antibody and a biotinylated, affinity-purified rabbit antiserum directed against recombinant human BDNF was used as the reporter antibody (Radka et al., 1996).

Quantitation of monoamines by HPLC. An aliquot of the homogenate prepared for the BDNF ELISA was taken before centrifugation. It was rehomogenized with perchloric acid added to $0.1 \mathrm{~N}$ and centrifuged at $10,000 \times g$ for $10 \mathrm{~min}$. The supernatant was transferred to an Ultrafree-MC $10 \mathrm{kDa}$ cutoff filter unit and spun at $10,000 \times g$ for $10 \mathrm{~min}$. Twenty microliters of sample were injected onto a reverse-phase $3 \mathrm{~mm}$ ODS HR-80 catecholamine HPLC column, and the separated dopamine and norepinephrine were detected electrochemically using eight detectors of the coulometric system (ESA, Waltham, MA) (Gamache et al., 1993). 


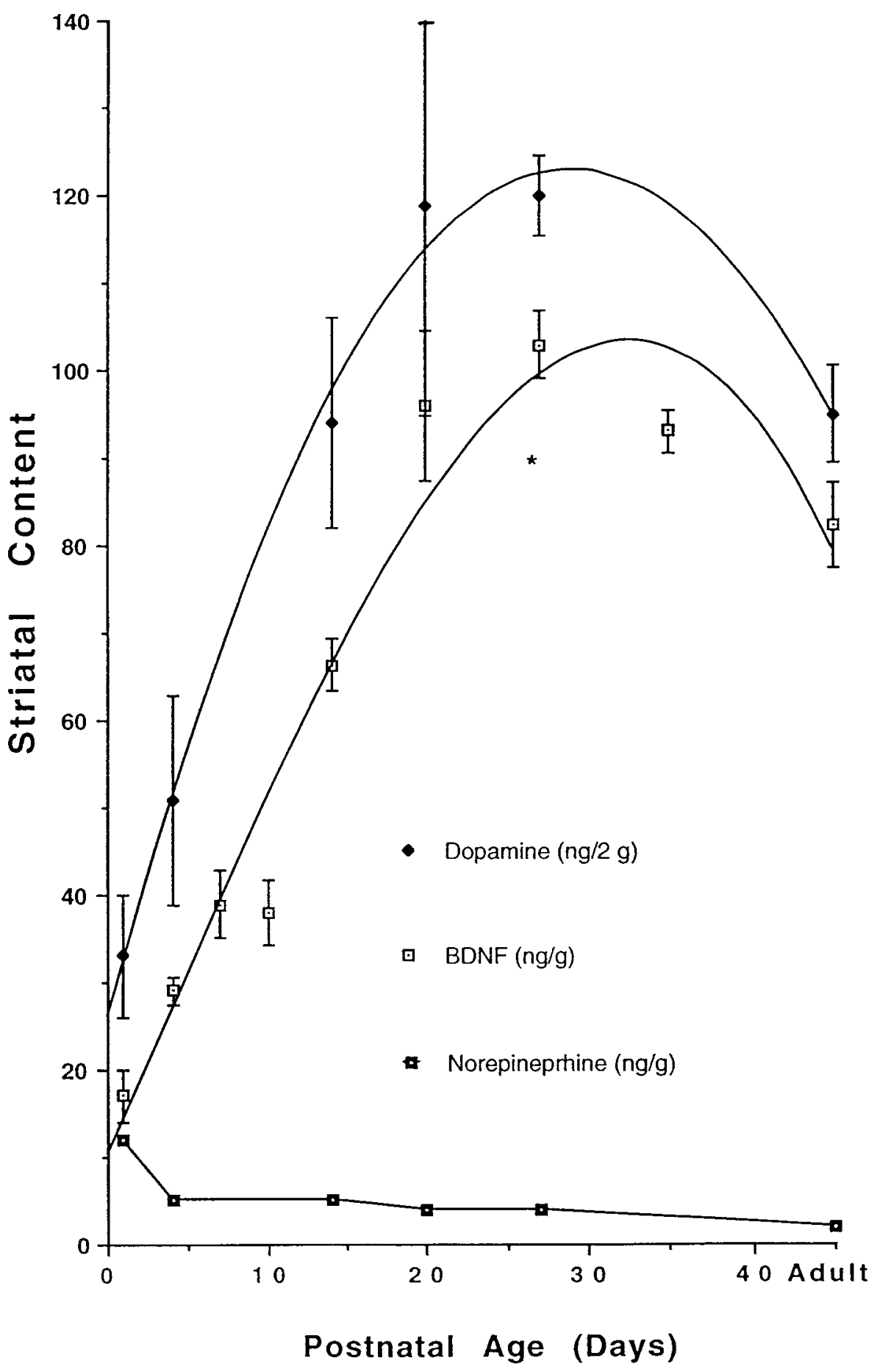

Figure 1. Ontogeny of BDNF, dopamine, and norepinephrine in rat striatum. Values are mean \pm SEM expressed as nanograms per gram of striatal tissue (for dopamine, $\mathrm{ng} / 2 \mathrm{gm}$ of striatal tissue); $n=4-5$ /group. Adults were $45 \mathrm{~d}$ of age. ${ }^{*} p<0.02$ versus adult for BDNF content (Dunnett's test).

Immunohistochemical techniques. All rats were deeply anesthetized with sodium pentobarbital and perfused transcardially with ice-cold saline followed by $4 \%$ paraformaldehyde. The brains were post-fixed overnight in $4 \%$ paraformaldehyde and placed in $30 \%$ sucrose. Brain sections $(40 \mu \mathrm{m})$ were cut on a sliding microtome and stored in cryoprotectant at $-20^{\circ} \mathrm{C}$ (Watson et al., 1986). For immunocytochemical detection of tyrosine hydroxylase (TH) (Yurek et al., 1996), free-floating sections were incubated overnight in mouse antisera containing a monoclonal antibody against TH (1:8000; Chemicon, Temecula, CA). The sections were then incubated in an affinity-purified biotinylated rabbit anti-mouse IgG secondary antibody (1:400; Chemicon) and then incubated in an avidin-biotin-peroxidase complex (Vector Laboratories, Burlingame, CA). Staining was completed by placing the sections in $0.003 \% \mathrm{H}_{2} \mathrm{O}_{2}$ that contained diaminobenzidine chromogen and nickel ammonium sulfate to visualize the peroxidase-catalyzed reaction product.

Quantification of fiber outgrowth. Fiber outgrowth from transplants was quantitated using methodology from a previous study (Yurek et al., 1996). Low-power $(2 \times)$ images of brain sections containing $\mathrm{TH}$ immunostained transplants were captured via a video frame grabber and stored to computer disk as TIFF files. Image files were analyzed on a Macintosh IIsi computer using the public domain National Institutes of Health Image program. Coarse fibers, cell bodies, and fine granules immunostained for $\mathrm{TH}$ were distinguished from one another by their detection at different density levels. For example, fine TH-IR elements distributed diff usely within the host striatum were measured by adjusting density levels to exclude TH-IR cell bodies, densely stained coarse TH-IR fibers, and background from the calculation. Measurements were 


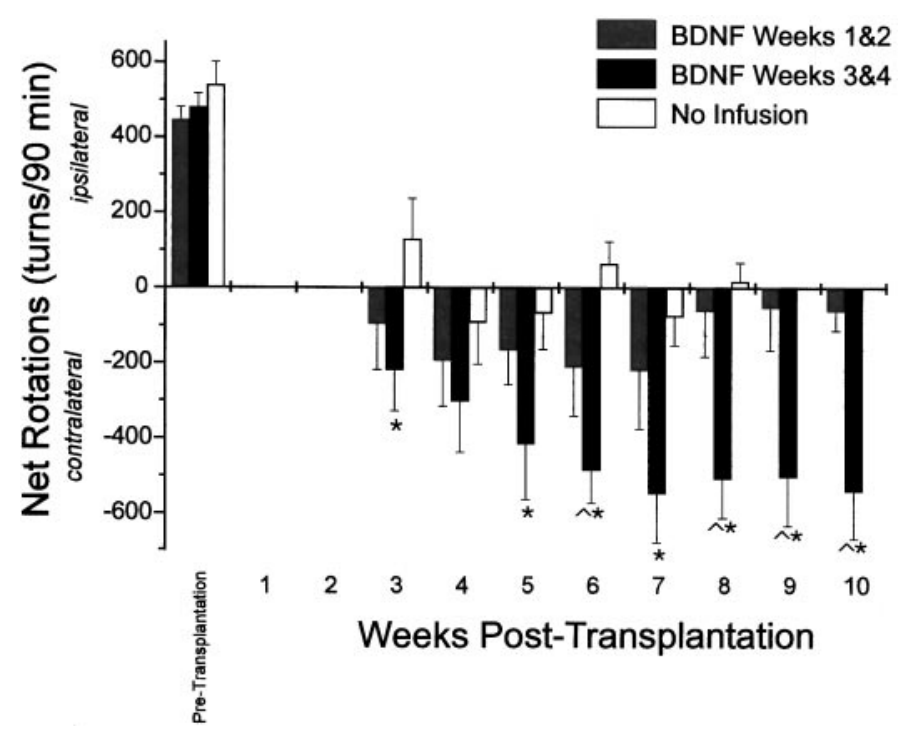

Figure 2. Amphetamine-induced rotational behavior for animals with transplants of fetal ventral mesencephalon and no infusion $(n=12)$ or infusion of BDNF during weeks 1 and $2(n=10)$ or weeks 3 and 4 $(n=9)$ after the transplantation. Vertical bars represent mean rotational scores $( \pm$ SEM $)$ accumulated over 90 min after an injection of amphetamine $(5.0 \mathrm{mg} / \mathrm{kg}$, i.p.). Brain-derived neurotrophic factor $(3.0 \mu \mathrm{g} / \mu \mathrm{l})$ was continuously infused into the transplant site at a rate of $0.5 \mu \mathrm{l} / \mathrm{hr}$ for 2 weeks. Data were analyzed using ANOVA with repeated measures; main effects of treatment $\left[F_{(2,28)}=22.11 ; p<0.001\right]$ and time $\left[F_{(8,224)}\right.$ $=105.44 ; p<0.001]$ were significant, and the treatment $\times$ time interaction $\left[F_{(16,224)}=7.71 ; p<0.001\right]$ was significant. ${ }^{*} p<0.05$ versus no infusion; $p<0.05$ versus 1 and 2 weeks.

made in sections in which the transplanted tissue could be visualized, and three coronal sections showing maximal fiber outgrowth were chosen for evaluation. An average area of fine fiber outgrowth was calculated for each animal. All density measurements were made with the observer blind to the treatment.

\section{RESULTS}

Ontogeny of BDNF and catecholamines in the striatum

The striatal concentrations of BDNF protein and dopamine were at low levels at P1 and increased by approximately sixfold to attain peak levels by P27 (Fig. 1). The effect of age on BDNF protein levels was statistically significant $\left[F_{(8,36)}=57.0 ; p<\right.$ $0.0001]$. The levels of BDNF at P27 exceeded those obtained at P45 (Dunnett's $t$ multiple comparison test, $t\{1,8 \mathrm{df}\}=3.3 ; p<$ 0.02). Striatal levels of BDNF protein and dopamine were highly correlated $(r=+0.99)$ during the postnatal ages. Dopamine and BDNF reached 99 and $93 \%$ of peak striatal levels, respectively, at P20. Concentrations of norepinephrine, a catecholamine neurotransmitter associated with the sympathetic innervation of blood vessels in this structure, did not increase in concentration after birth.

\section{BDNF infusion at 1 and 2 versus 3 and 4 weeks after the transplantation}

Before transplantation, all animals consistently rotated in a direction ipsiversive to the lesioned hemisphere after being injected with D-amphetamine (Fig. 2). Up to 3 weeks after the transplantation, the animals that received no infusion or BDNF infusion during weeks 1 and 2 after the transplantation exhibited net rotational scores that were close to zero (Fig. 2). From 5 to 10 weeks after the transplantation, animals infused with BDNF during weeks 3 and 4 produced more amphetamine-stimulated contraversive rotations than did the uninfused animals or those inf used with BDNF during weeks 1 and 2 (Fig. 2).

The density of TH-IR staining in the host tissue surrounding transplants infused with BDNF during the 1 and 2 week period after the transplantation appeared similar to that observed in transplants of uninf used animals (Fig. 3) and did not exceed the calculated value of fiber outgrowth for uninfused transplants (Fig. 4). On the other hand, transplants infused with BDNF during weeks 3 and 4 after the transplantation showed denser (Fig. 3C,D) and larger areas of TH-IR staining within the host tissue compared with that in the 1 and 2 week infusion group or the uninf used animals (Fig. 4). Estimates of TH-IR cell counts within the transplant did not reveal a statistically significant difference between the no inf usion, the week 1-2 inf usion, or the week 3-4 infusion groups (see Fig. 6).

\section{BDNF infusion: 7 and 8 weeks after the transplantation}

Transplanted animals that received an infusion of PBS during weeks 7 and 8 after the transplantation exhibited the expected and essentially complete attenuation of amphetamine-induced rotational behavior (Fig. 5), similar to that seen in the uninf used animals of a previous experiment (Fig. 2). In contrast, the infusion of BDNF during weeks 7 and 8 after the transplantation impaired transplant function, as demonstrated by a reappearance of amphetamine-induced ipsiversive rotations for several weeks after the BDNF infusion period (Fig. 5).

Transplants infused with BDNF during weeks 7 and 8 after the transplantation produced variable morphological results. Compared with the optimal transplant growth obtained with BDNF infusions during weeks 3 and 4, some transplants looked very small, contained few TH-IR cell bodies, and showed a reduced area of TH-IR fiber staining within the host tissue (Fig. 3E). Despite showing the typical reduction in rotational behavior to near-zero values during the sixth week after the transplantation, animals that subsequently received an infusion of BDNF during weeks 7 and 8 showed a reappearance of amphetamine-induced rotational behavior (Fig. 5). Other transplants appeared to have normal patterns of TH-IR staining in the cell bodies and fibers (Fig. $3 F$ ), yet these animals showed the reappearance of amphetamine-induced ipsilateral rotational behavior after the BDNF infusion period. No estimates of TH-IR cell counts were made for this group.

\section{DISCUSSION}

The present study investigated whether the timing of 2-week-long infusions of BDNF affected the fiber outgrowth and behavioral function of transplanted fetal ventral mesencephalic dopamine neurons and how such timing was related to the normal ontogeny of BDNF and dopamine innervation in the striatum. We identified a 2 week period immediately after the transplantation in which BDNF was ineffective compared with the effects in untreated grafts. In contrast, a delayed period of BDNF starting 2 weeks after the transplantation greatly potentiated fiber outgrowth and behavioral function. A more delayed BDNF infusion period that started 7 weeks after the transplantation was deleterious to behavioral improvement and, in some cases, had an adverse effect on the morphological development of transplant TH-IR neurons. The study also demonstrated a concordant and predominantly postnatal ontogeny of dopamine nerve terminal ingrowth and BDNF protein levels in the rat striatum. Thus, the optimal effect of BDNF on the development of grafted dopamine neurons occurred at a transplant epoch when the greatest striatal 

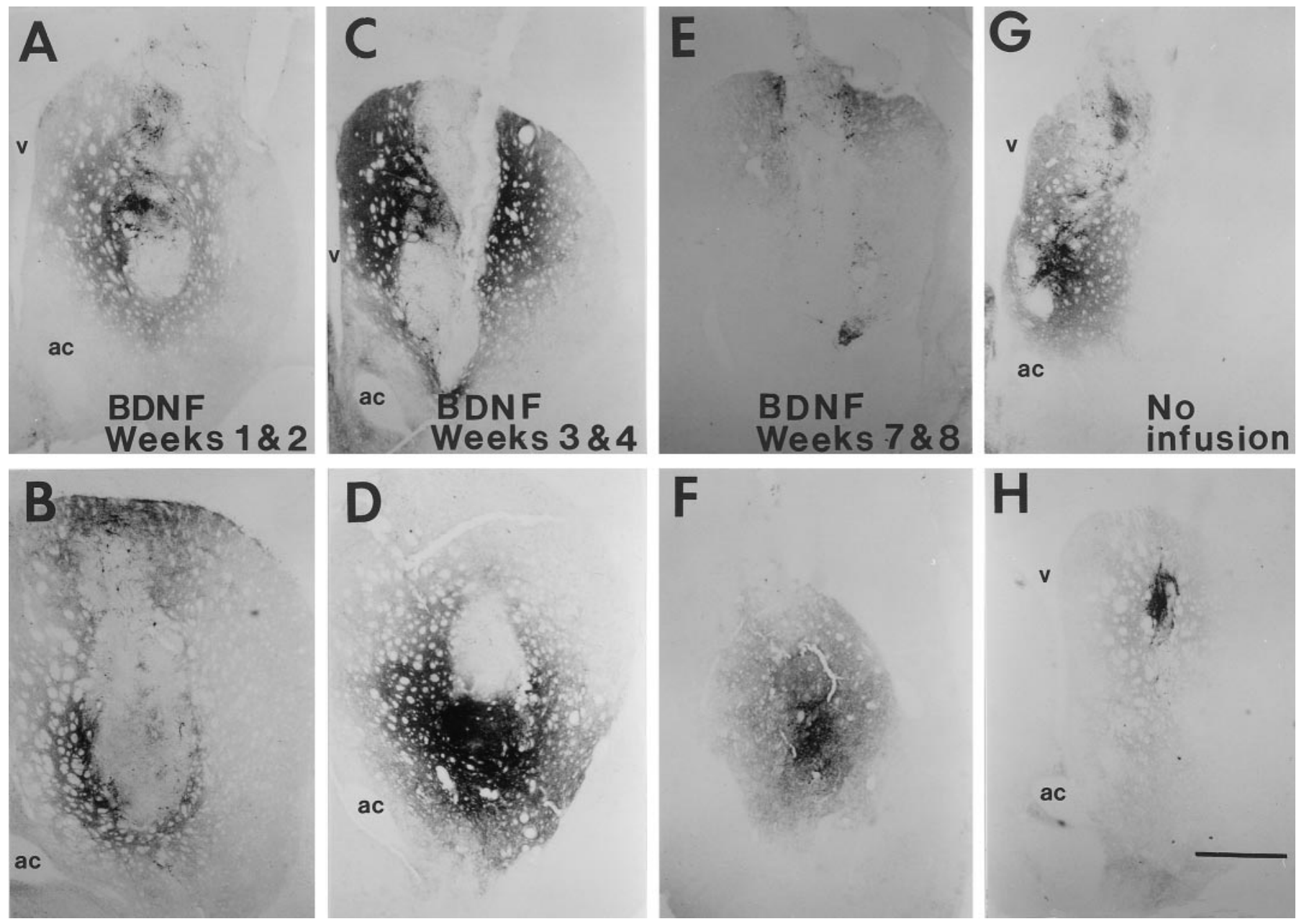

Figure 3. Representative tyrosine hydroxylase-immunostained brain sections collected from the striata of dopamine-denervated, transplanted rats that received a continuous infusion of BDNF during weeks 1 and $2(A, B), 3$ and $4(C, D)$, or 7 and $8(E, F)$ after the transplantation or no infusion $(G, H)$. Brain-derived neurotrophic factor $(3.0 \mu \mathrm{g} / \mu \mathrm{l})$ was continuously inf used into the transplant site at a rate of $0.5 \mu \mathrm{l} / \mathrm{hr}$ for a total of 2 weeks for each treatment group with the exception of the no-inf usion group. All photomicrographs were taken at the same magnification $(5 \times)$. $v$, Ventricle; $a c$, anterior commissure. Scale bar, $1.0 \mathrm{~mm}$.

ingrowth of dopamine nerve fibers into the striatum and striatal BDNF normally occurs. It will be interesting to determine whether the growth and behavioral efficacy of other growth factor adjuvants for fetal nigral transplants, such as GDNF (Strömberg et al., 1993; Rosenblad et al., 1996; Wang et al., 1996) or bFGF (Steinbusch et al., 1990; Giacobini et al., 1991; Mayer et al., 1993a; Takayama et al., 1995; Zeng et al., 1996), can be optimized by similar delivery timing strategies. If so, the optimal delivery of either factor may occur at the time of transplantation or soon thereafter because striatal GDNF (Strömberg et al., 1993) and bFGF mRNA and protein levels reach near-adult levels around birth.

Animals that receive an inf usion of BDNF into the transplant during weeks 3 and 4 after the transplantation (present findings) or weeks 1 through 4 after the transplantation (Yurek et al., 1996) show a larger ingrowth of dopamine nerve fibers surrounding the transplant, a larger region of coarse fiber outgrowth extending from the transplant and into the striatal neuropil, and an overcorrection of amphetamine-induced rotational behavior that persists for at least 6 weeks after the withdrawal of BDNF. Thus, it seems that BDNF must be infused during a 2 week period that starts at a transplant age of 1 week after birth.

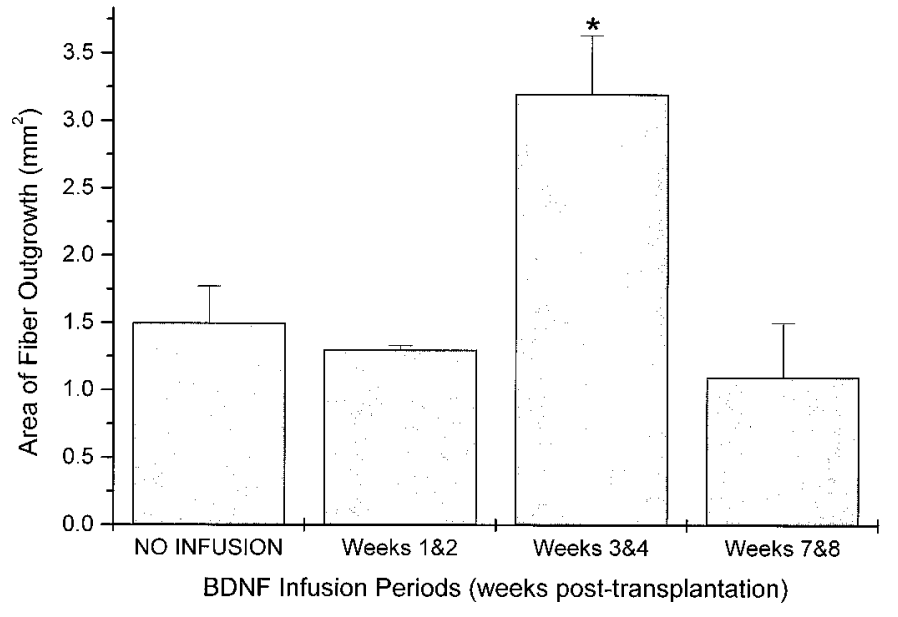

Figure 4. The area of TH-IR fiber outgrowth from transplanted fetal ventral mesencephalon was measured for each animal using three coronal levels of striata that showed the maximal fiber outgrowth. Each vertical bar represents the average ( \pm SEM) for groups composed of the following animals: no infusion $(n=12)$ and 1 and 2 weeks $(n=10), 3$ and 4 weeks $(n=9)$, or 7 and 8 weeks $(n=7)$ infusion. Data were analyzed using ANOVA $\left[F_{(3,16)}=5.05 ; p<0.05\right] ;{ }^{*} p<0.05$ (Tukey test). 

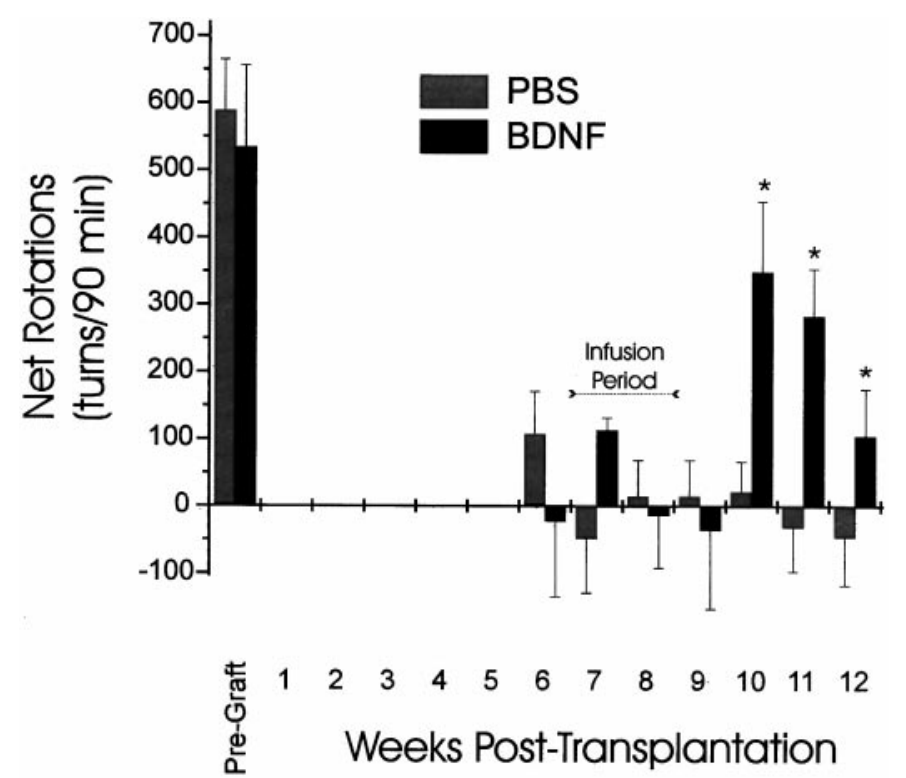

Figure 5. Amphetamine-induced rotational behavior of animals that received transplants of fetal ventral mesencephalon and infusion of PBS $(3.0 \mu \mathrm{g} / \mu \mathrm{l} ; n=6)$ or BDNF $(36 \mu \mathrm{g} / \mathrm{d} ; n=7)$ during weeks 7 and 8 after the transplantation. Bars represent mean net rotational scores \pm SEM for $90 \mathrm{~min}$ after an injection of amphetamine $(5.0 \mathrm{mg} / \mathrm{kg}$, i.p.). Data were analyzed using ANOVA with repeated measures; the treatment $\times$ time interaction $\left[F_{(7,77)}=3.67 ; p<0.01\right]$ was significant; ${ }^{*} p<0.05$ versus PBS (Tukey test).

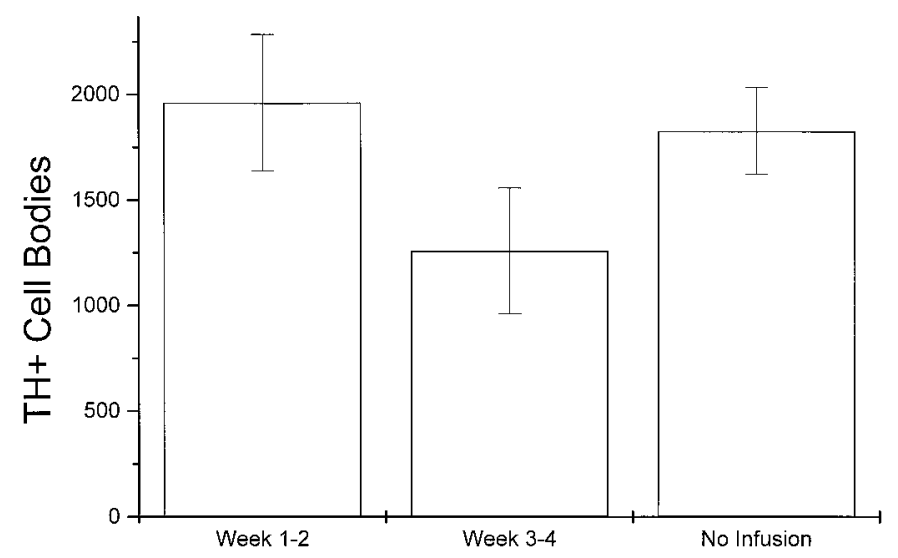

Figure 6. Estimates of TH-IR cell bodies in transplants for three different BDNF inf usion groups: week 1-2 infusion $(n=5)$, week 3-4 inf usion $(n=5)$, and no infusion $(n=5)$. Vertical bars represent the total number ( \pm SEM) of TH-IR cell bodies counted throughout the transplant in every other $40 \mu \mathrm{m}$ section. Statistical analysis (ANOVA) revealed no significant differences between treatment groups $\left[F_{(2,14)}=2.5 ; p>0.10\right]$.

The number of surviving TH-IR cell bodies within the transplant does not appear to be increased by BDNF during any infusion period and in some instances appear lower than the number observed in the no-infusion control group. That the extent of TH-IR fiber outgrowth was nearly doubled in these same animals suggests that BDNF may act as a target-derived neurotrophic factor that supports the growth of dopaminergic terminals but not the survival of dopamine neurons, at least under these in vivo conditions. Estimates of TH-IR cell bodies within transplants revealed that BDNF inf usions during the first month after the transplantation did not improve survival, and this is consistent with a previous study (Sauer et al., 1993).
There was a remarkably similar ontogeny in striatal BDNF protein and dopamine. Our finding with dopamine corroborates previous work that shows that striatal dopamine is normally low at birth and increases dramatically during the first postnatal month, particularly during postnatal weeks 2-4 (Loizou, 1972; Hattori and McGeer, 1973; Coyle and Campochiaro, 1976). During postnatal weeks $2-4$, dopaminergic varicosities show a rapid increase, and dopaminergic terminal fields form an adult pattern (Voorn et al., 1988). During this same period, endogenous BDNF appeared at the same rate, presumably because of a concomitant innervation of striatum by corticostriatal and nigrostriatal neurons. These two afferent systems account for essentially all of the BDNF present in the adult striatum (Altar et al., 1997). The failure of BDNF null mutants to demonstrate a loss of striatal dopamine or tyrosine hydroxylase-positive dopaminergic nerve terminals at P15 (Jones et al., 1994; S. J. Weigand and C. A. Altar, unpublished observations) indicates either that BDNF is not essential for the development of nigrostriatal dopamine neurons or that regulation becomes important after P15, when the BDNF null mutants usually die. The ability of BDNF to augment dopamine fiber growth when BDNF is delivered to the transplants during their second and third postnatal week, but not during the 2 weeks before this time, argues for a delayed role of BDNF in the maturation of nigrostriatal dopamine neurons that is not observable in the BDNF null mutant mice.

Although we observed an improvement of both functional recovery and fiber outgrowth in transplanted animals that received continuously infused BDNF, Sauer et al. (1993) observed only slight improvement in functional recovery after intermittent infusion of BDNF into the transplant site and did not observe improved fiber outgrowth from transplants. Although methodological differences exist between our study and that performed by Sauer et al. (1993), including the dose and mode of BDNF delivery and the type of transplant, Sauer et al. inf used BDNF for only 2 weeks and immediately after the transplantation. We too did not observe a significant effect of BDNF on rotational behavior or fiber outgrowth with such an immediate infusion paradigm. Thus, it is possible that weeks 3 and 4 after the transplantation are a critical period for the ability of BDNF to stimulate fiber outgrowth of transplanted dopaminergic neurons. This period corresponds to postnatal weeks 2 and 3 of the transplant and may be associated with a maturation of the transplanted tissue to respond to exogenous BDNF. Evaluation of trkB mRNA or ${ }^{125} \mathrm{I}-\mathrm{BDNF}$ binding to the transplant as a function of time after in vivo grafting is one method of evaluating this possibility.

It is worth considering why delaying the inf usion of BDNF into the transplant site until weeks 7 and 8 after the transplantation either did not improve or in some cases lessened the morphological and functional aspects of the transplant. Both dopamine content and BDNF protein in the striatum are at near-maximal levels at P20 and throughout adulthood. Thus, BDNF levels per se are not predictive of when BDNF will have an optimal effect on the transplant. It is unclear why BDNF infusions at weeks 7 and 8 after the transplantation increased ipsiversive rotational behavior after amphetamine treatment for most animals in this group. Morphological analysis indicates that in some animals, BDNF inf usions at this time point may be detrimental to the survival of the transplant (Fig. $3 E$ ), whereas transplants in other animals maintained a normal morphological appearance (Fig. $3 F$ ). It is unlikely the increase in ipsiversive rotational behavior is strictly a result of cell loss within the transplant for several reasons. First, not all BDNF-infused transplants looked morphologically im- 
paired. Second, if BDNF infusions produced cell loss in transplants during weeks 7 and 8 after the transplantation, then ipsiversive rotational scores most likely would have increased and then stabilized at this higher level. However, the increase in ipsiversive rotations seemed to be a transient phenomenon because rotational scores initially increased and then declined toward preinfusions levels by the 12 th week after the transplantation. This indicates that factors other than cell loss are responsible for the transient change in rotational behavior. It is conceivable that BDNF inf usions at this time point induce acute changes in the neurochemical activity of dopaminergic and/or nondopaminergic neurons within the transplant.

In conclusion, these data provide evidence that transplanted fetal dopamine neurons respond optimally to exogenous BDNF when transplanted neurons are at an age that corresponds to the period during normal development when dopamine and BDNF increase dramatically within the striatum. The period P7-P28 may be an epoch when dopamine neurons are most responsive to the direct effects of endogenous or exogenous BDNF. Alternatively, BDNF infusion may have stimulated other neurotrophic mechanisms in the host or transplant that ultimately improves survival and fiber outgrowth of TH-IR neurons. Although in vitro studies have demonstrated a direct neurotrophic effect of BDNF on fetal dopaminergic neurons (Hyman et al., 1991; for review, see Altar et al., 1996), BDNF may also have trophic effects on fetal nigral neurons in vivo via its effects on neurons in the host striatum or within the graft itself. Such neurons include GABA neurons in the graft (Hyman et al., 1994; Spenger et al., 1995; Studer et al., 1996), cholinergic interneurons (Knüsel et al., 1991), and serotonergic nerve terminals in the host system (MartinIversen et al., 1994). Other neurotrophic factors may also provide trophic support to neurons via glia, as observed by Engele and Bohn (1991) for the neurotrophic effect of bFGF on culture dopaminergic neurons. In such ways, the infusion of one neurotrophic factor may initiate a cascade of neurotrophic activity that provides further support for transplanted neurons. Insights into such secondary actions can be studied by measuring the effects growth factors have on the expression of other neurotrophic factors and their receptors in the host and transplanted tissue. Because of the complexities in timing and dosing and the potential involvement of other cell types, the use of growth factors as adjuvants for fetal nigral transplants needs to be determined empirically for each factor.

\section{REFERENCES}

Altar CA, Wiegand SJ, Lindsay RM, Cedarbaum JM (1996) Neurotrophic factors: towards a restorative therapy of Parkinson's disease. In: Neuroprotective approaches to the treatment of neurodegenerative disease (Olanow CW, Jenner P, Youdim M, eds), pp 160-180. London: Academic.

Altar CA, Cai N, Bliven T, Juhasz M, Connor JR, Acheson A, Lindsay RM, Wiegand SJ (1997) Anterograde transport of BDNF and its role in the brain. Nature 389:856-860.

Coyle JT, Campochiaro P (1976) Ontogenesis of dopaminergiccholinergic interactions in the rat striatum: a neurochemical study. J Neurochem 27:673-678.

Ebendal T (1992) Function and evolution in the NGF family and its receptors. J Neurosci Res 32:461-470.

Engele J, Bohn MC (1991) The neurotrophic effects of basic fibroblast growth factors on dopaminergic neurons in vitro are mediated by mesencephalic glia. J Neurosci 11:3070-3078.

Gall CM, Gold SJ, Isackson PJ, Seroogy KB (1992) Brain-derived neurotrophic factor and neurotrophin-3 mRNAs are expressed in ventral midbrain regions containing dopaminergic neurons. Mol Cell Neurosci 3:56-63.
Gamache PH, Ryan E, Svendsen CN, Murayama K, Acworth IN (1993) Simultaneous measurement of monoamines, metabolites and amino acids in brain tissue and microdialysis perfusates. J Chromatogr 614:213-220.

Giacobini MMJ, Hoffer BJ, Zerbe G, Olson L (1991) Acidic and basic fibroblast growth factors augment growth of fetal brain tissue grafts. Exp Brain Res 86:73-81.

Giacobini MMJ, Alström S, Funa K, Olson L (1993) Differential effects of platelet-derived growth factor isoforms on dopamine neurons in vivo. I. Supports cell survival. II. Enhances fiber formation. Neuroscience 57:923-929.

Haque NSK, Hlavin M-L, Fawcett JW, Dunnett SB (1996) The neurotrophin NT4/5, but not NT3, enhances the efficacy of nigral grafts in a rat model of Parkinson's disease. Brain Res 712:45-52.

Hattori T, McGeer PL (1973) Synaptogenesis in the corpus striatum of infant rat. Exp Neurol 38:70-79.

Hyman C, Hoffer M, Barde Y-A, Juhasz M, Yancopoulus GD, Squinto SP, Lindsay RM (1991) BDNF is a neurotrophic factor for dopaminergic neurons of the substantia nigra. Nature 350:230-232.

Hyman C, Juhasz M, Jackson C, Wright P, Ip NY, Lindsay RM (1994) Overlapping and distinct actions of the neurotrophins BDNF, NT-3, and NT-4/5 on cultured dopaminergic and GABAergic neurons of the ventral mesencephalon. J Neurosci 14:335-347.

Jones KR, Farinas I, Backus C, Reichardt LF (1994) Targeted disruption of the BDNF gene perturbs brain and sensory neuron development but not motor neuron development. Cell 76:989-999.

Knüsel B, Winslow JW, Rosenthal A, Burton LE, Seid DP, Nikolics K, Hefti F (1991) Promotion of central cholinergic and dopaminergic neuron differentiation by brain-derived neurotrophic factor but not neurotrophin-3. Proc Natl Acad Sci USA 88:961-965.

Lindsay RM, Altar CA, Cedarbaum JM, Hyman C, Wiegand SJ (1993) The therapeutic potential of neurotrophic factors in the treatment of Parkinson's disease. Exp Neurol 124:103-118.

Lindsay RM, Wiegand SJ, Altar CA, DiStefano PS (1994) Neurotrophic factors: from molecule to man. Trends Neurosci 17:182-190.

Loizou LA (1972) The postnatal ontogeny of monoamine-containing neurones in the central nervous system of the albino rat. Brain Res 40:395-418.

Martin-Iversen MT, Todd KG, Altar CA (1994) Brain-derived neurotrophic factor and neurotrophin-3 activate striatal dopamine and serotonin metabolism and related behaviors: interactions with amphetamine. J Neurosci 14:1262-1270.

Mayer E, Dunnett SB, Pellietteri R, Fawcett JW (1993a) Basic fibroblast growth factor promotes the survival of embryonic mesencephalic dopaminergic neurons. I. Effects in vitro. Neuroscience 56:370-388.

Mayer E, Fawcett JW, Dunnett SB (1993b) Basic fibroblast growth factor promotes the survival of embryonic ventral mesencephalic dopaminergic neurons. II. Effects on nigral transplants in vivo. Neuroscience 56:389-398.

Meakin SO, Shooter EM (1992) The nerve growth factor family of receptors. Trends Neurosci 15:323-331.

Miranda RC, Sohrabji F, Toran-Allerand CD (1993) Neuronal colocalization of mRNAs for neurotrophins and their receptors in the developing nervous system suggests a potential for autocrine interactions. Proc Natl Acad Sci USA 90:6439-6443.

Olanow CW, Kordower JH, Freeman TB (1996) Fetal nigral transplantation as a therapy for Parkinson's disease. Trends Neurosci 19:102-109.

Radka SF, Holst RA, Fritsche M, Altar CA (1996) Presence of brainderived neurotrophic factor in brain and human and rat but not mouse serum detected by a sensitive and specific immunoassay. Brain Res 709:122-130.

Rosenblad C, Martinez-Serrano A, Björklund A (1996) Glial cell linederived neurotrophic factor increases survival, growth and function of intrastriatal fetal nigral dopaminergic grafts. Neuroscience 75:979-985.

Sauer H, Fischer W, Nikkhah G, Wiegand SJ, Brundin P, Lindsay RM, Björklund A (1993) Brain-derived neurotrophic factor enhances function rather than survival of intrastriatal dopamine cell-rich grafts. Brain Res 626:37-44.

Seroogy KB, Gall CM (1993) Expression of neurotrophins by midbrain dopaminergic neurons. Exp Neurol 124:119-128.

Spenger C, Hyman C, Studer L, Egli M, Evtouchenko L, Jackson C, Dahl-Jorgensen A, Lindsay RM, Seiler RW (1995) Effects of BDNF on dopaminergic, serotonergic, and GABAergic neurons in cultures of human fetal ventral mesencephalion. Exp Neurol 133:50-63. 
Squinto SP, Stitt TN, Aldrich TH, Davis S, Bianco SM, Radziejewski C, Glass DJ, Masiakowski P, Furth ME, Valenzuela DM, DiStefano PS, Yancopoulos GD (1991) trkB encodes a functional receptor for brainderived neurotrophic factor and neurotrophin-3 but not NGF. Cell 65:885-893.

Steinbusch HWM, Vermeulen RJ, Tonnaer JADM (1990) Basic fibroblast growth factor enhances survival and sprouting of fetal dopaminergic cells implanted in the denervated rat caudate-putamen: preliminary observations. Prog Brain Res 82:81-86.

Strömberg I, Björklund L, Johansson M, Tomac A, Collins F, Olson L, Hoffer B, Humpel C (1993) Glial cell line-derived neurotrophic factor is expressed in the developing but not adult striatum and stimulates developing dopamine neurons in vivo. Exp Neurol 124:401-412.

Studer L, Spenger C, Seiler RW, Othberg A, Lindvall O, Odin P (1996) Effects of brain-derived neurotrophic factor on neuronal structure of dopaminergic neurons in dissociated cultures of human fetal mesencephalon. Exp Brain Res 108:328-336.

Takayama H, Ray J, Raymon HK, Baird A, Hogg J, Fisher LJ, Gage FH (1995) Basic fibroblast growth factor increases dopaminergic graft sur vival and function in a rat model of Parkinson's disease. Nat Med 1:53-58.

Voorn P, Kalsbeek A, Jorritsma-Byham B, Groenewegen HJ (1988) The pre- and postnatal development of the dopaminergic cell groups in the ventral mesencephalon and the dopaminergic innervation of the striatum of the rat. Neuroscience 25:857-887.

Wang Y, Tien LT, Lapchak PA, Hoffer BJ (1996) GDNF triggers fiber outgrowth of fetal ventral mesencephalic grafts from the nigra to striatum in 6-OHDA-lesioned rats. Cell Tissue Res 286:225-233.

Watson Jr RE, Wiegand SJ, Clough RL, Hoffman GE (1986) Use of cryoprotectant to maintain long-term peptide immunoreactivity and tissue morphology in free-floating sections. Peptides 7:155-159.

Yurek DM, Lu W, Hipkens SB, Wiegand SJ (1996) BDNF enhances the functional reinnervation of the striatum by grafted fetal dopamine neurons. Exp Neurol 137:105-118.

Zeng BY, Jenner P, Marsden CD (1996) Altered motor function and graft survival produced by basic fibroblast growth factor in rats with 6-OHDA lesions and fetal ventral mesencephalic grafts are associated with glial proliferation. Exp Neurol 139:214-226. 